\title{
COMPLEX NETWORK-BASED INFORMATION SYSTEMS (CNIS) STANDARDS: Toward an Adoption Model
}

\author{
David Kelly \\ Joseph Feller \\ Patrick Finnegan \\ University College Cork \\ Cork, Ireland
}

\begin{abstract}
This paper proposes an adoption model for complex network-based information systems (CNIS) standards which extends current diffusion of innovation theory within a specific technological context, that of ambient intelligence (AmI). The issue of open and closed standards is especially important for networked information systems; however, a range of factors impact the adoption decision and challenge existing models of adoption. Such models are based on DOI theories that have their roots in more simplistic technological innovations. In order to extend the current view on adoption, the adoption context must be closely considered. Agile organizations must constantly survey the external environment to determine the potential of emerging technology. Open standards may make organizations less vulnerable to environmental flux due to uncertainties caused by the lack of transparency of proprietary standards. Accordingly, the proposed model moves toward providing a means to assess factors impacting the adoption of open and proprietary standards.
\end{abstract}

Keywords Emerging IS/IT, diffusion of innovation, standards adoption

\section{INTRODUCTION}

Organizational agility is based on two attributes: the prompt response to change in appropriate ways, and the ability to capitalize on the opportunities presented by change

Please use the following format when citing this chapter:

Kelly, David, Feller, Joseph, Finnegan, Patrick, 2006, in International Federation for Information Processing (IFIP), Volume 206, The Transfer and Diffusion of Information Technology for Organizational Resilience, eds. B. Donnellan, Larsen T., Levine L., DeGross J. (Boston: Springer), pp. 3-20. 
(Sharifi and Zhang 1999). Such changes are often the result of the emergence of new technologies (Thomke and Reinersten 1998). Traditionally, adoption and diffusion theory, such as Rogers' (1962), has been used as a means to explain the adoption issues surrounding external innovations. However, as new forms of network-based information systems become more complex, the role of interoperability standards as a means of enabling development requires careful consideration. Of particular importance is the emergence of the ambient intelligence (AmI) vision, which is based on a convergence of the related concepts, ubiquitous computing, ubiquitous communications, and intelligent user friendly interfaces (Ducatel et al. 2001). The concept of ubiquitous computing first emerged in the early 1990s (Weiser 1991) as a vision in which computers are removed from being objects of conscious attention. Rather than having computers operate in an environment in which people must adapt to them, they are integrated into the human environment.

A range of AmI based application spaces are currently under investigation. One such example is the development of intelligent transport systems (ITS) solutions by NEC (Maekawa 2004). Such systems rely on the integration of large numbers of sensors in the environment and in vehicles (up to 120), with integration occurring through open communications networks in order to provide services such as traffic, weather and road conditions recognition, position-based routing, and pedestrian transport services. Other examples of AmI application areas and usage scenarios are reported by Banavar and Bernstein (2002), Borriello et al.(2005), and Davies and Gellersen (2002).

The development of such systems results in a comparatively higher level of structural system complexity due to the need to integrate multiple heterogeneous devices (Garlan et al. 2002; Henricksen et al. 2001; Nakajima et al. 2002) or other system components (Davies and Gellersen 2002; Henricksen et al. 2001; Islam and Fayad 2003; Lassila 2002). While interoperability standards play a role in facilitating or inhibiting the technical development of systems, they also possess inherent economic and social characteristics which can not only impact their adoption, but also shape the future adoption and diffusion of systems based upon them.

The objective of this paper is to propose a model of open versus closed standards adoption within the context of AmI technologies. In order to clarify the technological context in which such adoption occurs, the paper first develops a categorization of network-based information systems based on their underlying structural complexity and defines three types. Following an examination of existing research on IT standards, existing extensions to DOI theory and the challenges of using such theory to account for adoption issues under certain technological contexts are then discussed. The paper then proposes an extended model for standards adoption, based on existing adoption and diffusion theory. The paper concludes by proposing that the model address issues relevant to the adoption of open or closed technical interoperability standards in the context of emergent complex network-based technologies.

The research approach used in the paper is a literature survey. Literature surveys have been employed by researchers in the past as a means of assessing the current state of the art and structuring existing knowledge. The examination of the history of previous work in an area enables the determination of progress made (Drury and Farhoomand 1999). Their use also enables reflection on what has been achieved in the past, and what work is required in the future to further develop a field of study (Alvai 
and Carlson 1992). It has been argued that the structured identification of required future research directions is important to conduct on an on-going basis, particularly in an emerging research area (Culnan 1987). Such an approach has been used at both a disciplinary level, for example within Information Systems (Alvai and Carlson 1992; Claver et al. 2000; Chen and Tan 2004; Drury and Farhoomand 1999; Orlikowski and Baroudi 1991), and at a thematic or subfield level (Romano and Fjermestad 2002). Earlier efforts at assessing the state of knowledge within an area (e.g., Information Systems) have limited the sample to a specific number of outlets in order to investigate the methods being used (e.g., Chen and Hirschheim 2004; Drury and Farhoomand 1999) or the paradigmatic focus into which the research falls (e.g., Chen and Hirschheim 2004; Orlikowski and Baroudi 1991). For this study, the review was limited by its aim of identifying studies that used DOI theory in a specific technological innovation context, that of base IT innovations (as per Lyytinen and Rose 2003).

\section{COMPLEX NETWORK-BASED INFORMATION SYSTEMS}

The use of the term complex network-based information system (CNIS) has its roots in complex systems literature. A complex system has been defined as one which is

made up of a large number of parts that interact in a non-simple way. In such systems, the whole is more than the sum of the parts....[and], given the properties of the parts and the laws of their interaction, it is not a trivial matter to infer the properties of the whole (Simon 1962, p. 468).

The complexity within such a system arises from the number of distinct parts of the system (Cilliers 1998; Langlois 2002), and the nature and number of interactions between these parts (Cilliers 1998; Ethiraj and Levinthal 2004; Langlois 2002). Following this logic, the classification of CNIS according to its structural complexity, similar to Lee and Xia (2002), is proposed as occurring along two dimensions as illustrated in Figure 1. The first of these dimensions is the scope of interactions that occur within the system as facilitated by the infrastructure upon which the system is based. Infrastructure in this context is defined from a technical perspective as being the basic support systems shared among users (Sirkemaa 2002). It thus includes technologies that provide data storage, system integration, connectivity, and security (Kumar 2004) as well as a capability for shared IT services implementation (Chung et al. 2003). A key characteristic of a complex system is dynamic, nonlinear interaction (Cilliers 1998). From an information systems perspective, one level of system complexity within a network-based IS can be seen in the level of complexity of the technical infrastructure used to support its interactions (i.e., business applications and services).

The second dimension used in the classification is the magnitude of the number of elements involved in the system (Cilliers 1998; Simon 1962). In IS, these elements correspond to both the business services and their enabling hardware elements, which interact throughout the system. The term services here is used in place of applications in order to signify a higher level of granularity (Lyytinen et al. 1998) from which the varied processes of the business performed (Chung et al. 2003) are being viewed. 


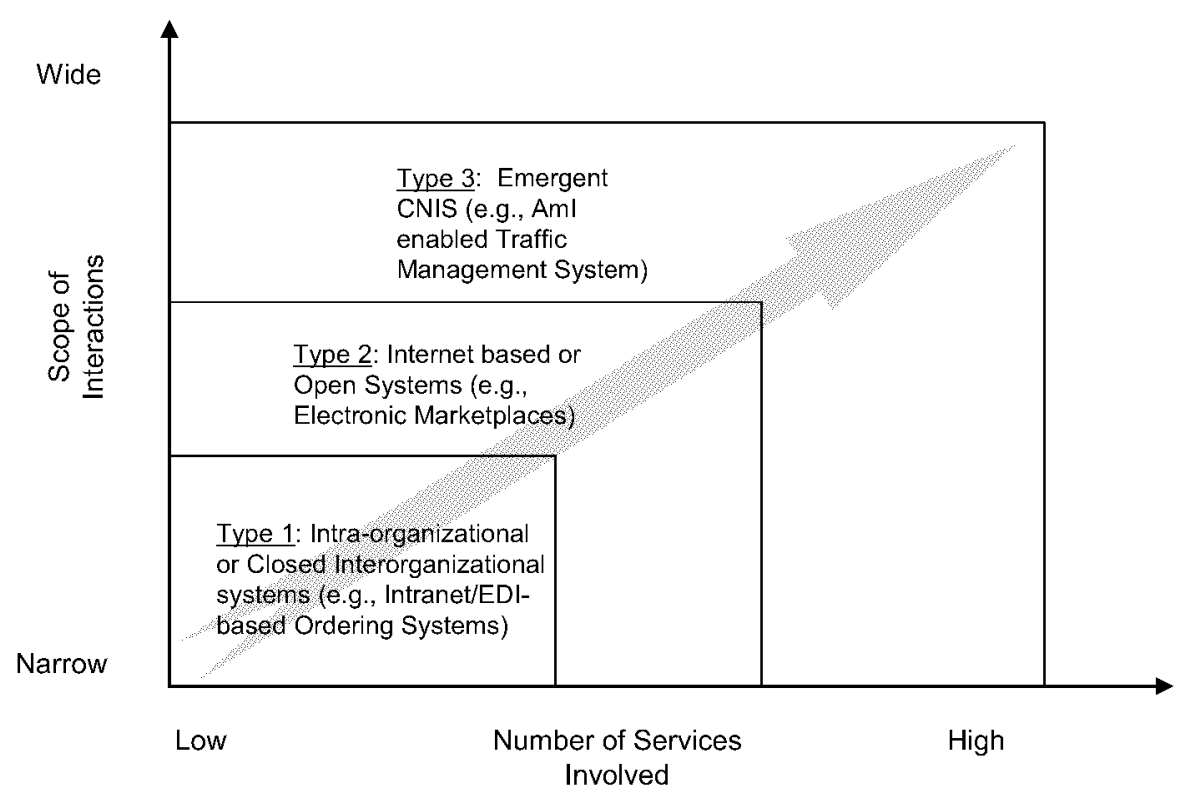

Note: The grey arrow illustrates increasing system complexity.

Figure 1. Dimensions of Structural Complexity in Network Information Systems

The application of these dimensions of complexity to network-based information systems can be seen in Figure 1, where three types of IS are represented visually as an illustration of the overlap between and changing complexity of IS of different types. The positioning of each type of IS is based on characteristics inherent in the system's design and evolution, namely, the addition of elements and the technical IT infrastructures required to facilitate element interactions. This classification offers an alternative perspective of IS by focusing on the underlying structure, rather than classification based on the types of IS users involved or the application domains. Such a perspective is useful in this context as it highlights issues relating to the underlying composition of the system, such as the role of standards.

Type 1 network IS shows the characterization of intra-organizational systems and closed interorganizational systems as having the lowest comparative level of structural complexity. The implementation of intra-organizational systems can lead to a degree of complexity. However, a degree of control can be exerted as the implementation is limited to a single organizational setting. This control is possible due to the knowledge held by those implementing the system (i.e., management services or technology vendor) and the confined nature of the system itself. Closed interorganizational systems, such as EDI-based systems, are also categorized as Type 1 due to their comparatively low level of structural complexity. This lower level of complexity is evident from the scale and type of interactions present in such networks (i.e., primarily point-to-point), as discussed by Christiaanse et al. (2004). 
Type 2 systems have a higher comparative level of structural complexity. In practical terms, such systems are implemented as Internet-based or other forms of open systems that allow the ad hoc addition of network elements. The ability to facilitate ad hoc expansion requires an underlying infrastructure capable of high levels of dynamic nonlinear interaction in order to function. In the case of open systems, such an infrastructure is enabled through the use of compatibility standards and modularity in system design.

Type 3 systems have the highest comparative level of structural complexity, and are labeled complex network-based information systems (CNIS). It is within this category that emerging IS/IT supporting ambient intelligence are positioned. CNIS are based on the integration of a variety of heterogeneous technical infrastructures in order to provide a high number of services, for example, the use of multiple network communications protocols to provide a platform for multiple integrated services to users.

The structural complexity of CNIS to support AmI is evident from key features such as mobility, unobtrusiveness, and context awareness, resulting in the need for high levels of interaction and large numbers of services, as illustrated in Table 1. Mobility enables the user to move seamlessly through the environment with services changing depending on the users location (Lyytinen and Yoo 2002). Unobtrusiveness is achieved through the removal of the computer from the user's conscious attention (Abowd and Mynatt 2000; Ducatel et al. 2001). Contextual awareness refers to applications that are capable of altering their behavior in response to contextual information from the user (Abowd et al. 2002; Prekop and Burnett 2003). Interoperability standards are required to facilitate the development of such structurally complex systems. Thus diffusion theories and adoption models must consider such standards as base IT innovations.

\section{TECHNICAL, BUSINESS, AND SOCIAL PERSPECTIVES ON STANDARDS}

Standards as base IT innovations are the underlying technologies used by IS service providers and are antecedents to innovation in the other classifications (Lyytinen and Rose 2003).

Research in the area of standards has taken place from a variety of perspectives, with differing views of the role and impacts felt by standards adoption. Although not always mutually exclusive, these perspectives can be broadly classified as falling into one of three categories: technical, business and economic, or social. It has become evident that the integration of these perspectives is particularly important in relation to the adoption of standards for CNIS. The need for such a combined view emerges from the fact that reliance on one perspective alone can give an incomplete or inaccurate picture of how the complex issues interact (Iversen 2001; Williams 1999).

From a technical perspective, the role of standards is viewed primarily as a means of facilitating interoperability throughout a system (e.g., Christiaanse et al. 2004; Chung et al. 2003; Damsgaard and Truex 2000; Sirkemaa 2002; Strand et al. 1994), and enabling system scalability in the later stages of the technology's diffusion (Helal 2005; Strand et al. 1994). Stegwee and Rukanova (2003) identify three levels of technical interoperability standards. First, interconnectivity standards enable systems to commu- 
Table 1. CNIS to Support Ambient Intelligence

\begin{tabular}{|c|c|c|c|}
\hline \multicolumn{4}{|c|}{ CNIS Characteristics } \\
\hline \multirow{4}{*}{ 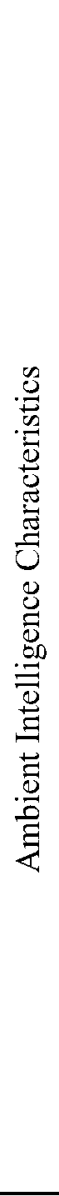 } & & $\begin{array}{l}\text { Large Number of } \\
\text { Elements }\end{array}$ & Wide Scope of Interaction \\
\hline & $\begin{array}{l}\text { Context } \\
\text { Awareness }\end{array}$ & $\begin{array}{l}\text { Enabled by information } \\
\text { from combinations of } \\
\text { sources, for example, } \\
\text { human and software agent } \\
\text { actors, RFID systems, } \\
\text { environmental systems } \\
\text { (e.g., sensor networks, } \\
\text { CCTV), location aware } \\
\text { systems (e.g., GPS, GSM), } \\
\text { distributed databases, } \\
\text { ambient displays. }\end{array}$ & $\begin{array}{l}\text { - Requires interaction } \\
\text { between geographically and } \\
\text { technologically distinct } \\
\text { system elements } \\
\text { (Boddupalli et al. 2003). } \\
\text { - Dynamic Interaction } \\
\text { between elements required } \\
\text { to allow changing inter- } \\
\text { actions depending on } \\
\text { services required. }\end{array}$ \\
\hline & Mobility & $\begin{array}{l}\text { Enabled by use of multiple } \\
\text { communications systems } \\
\text { depending on requirements } \\
\text { (e.g., GPRS, Wi-Fi, } \\
\text { Bluetooth). }\end{array}$ & $\begin{array}{l}\text { Dynamic interaction } \\
\text { between elements required } \\
\text { to allow switching between } \\
\text { multiple communications } \\
\text { protocols depending on } \\
\text { requirements of the } \\
\text { user/system. }\end{array}$ \\
\hline & Unobtrusiveness & $\begin{array}{l}\text { Provision of unobtrusive/ } \\
\text { uninterrupted services } \\
\text { requires large numbers of } \\
\text { elements embedded in the } \\
\text { environment to allow con- } \\
\text { sistent access to enabling } \\
\text { systems (e.g., those } \\
\text { described as enabling } \\
\text { Context Awareness above). }\end{array}$ & $\begin{array}{l}\text { Supports constant service } \\
\text { access within and between } \\
\text { environments . }\end{array}$ \\
\hline
\end{tabular}

nicate with each other at the network level (i.e., communication standards such as TCP/IP). Second, interchangeability standards enable systems to exchange information at the presentation level (i.e., data representation standards such as ASCII, HTML, and XML). Final interoperability standards (see also Sprott 2000; Strand et al. 1994) enable systems to operate together as one through interoperability at the application level (i.e., interaction standards such as SOAP and SMTP). Technical interoperability standards can also be classified according to the "level of openness" (West 2004). Table 2 summarizes the differences between the development of open and closed standards. It would be inaccurate to assume that all open or all closed standards meet all criteria within the table as standards are best placed along an open-closed continuum.

The business and economic perspective on standards-oriented research puts forward the dominant view of the roles and impacts of standards. In the development stage of new technologies, this perspective has focused on the role and impact of standards on 
Table 2. Characteristics of Open Versus Closed Standard Development (Adapted from Krechmer 2005)

\begin{tabular}{|l|l|l|}
\hline & \multicolumn{1}{|c|}{$\begin{array}{c}\text { Completely Open } \\
\text { Standard }\end{array}$} & $\begin{array}{c}\text { Completely Closed } \\
\text { Standard }\end{array}$ \\
\hline Barriers to participation & No & Yes \\
\hline $\begin{array}{l}\text { Discussion of interests and } \\
\text { agreement found }\end{array}$ & Yes & Between members \\
\hline $\begin{array}{l}\text { Due process (use of balloting and } \\
\text { appeals) }\end{array}$ & Yes & Between members \\
\hline $\begin{array}{l}\text { Global standard for the same } \\
\text { capability }\end{array}$ & Yes & $\begin{array}{l}\text { At discretion of } \\
\text { members }\end{array}$ \\
\hline IPR available to all implementers & Yes & No \\
\hline Forum for presenting changes & Open & Closed \\
\hline $\begin{array}{l}\text { User/implementer access to draft } \\
\text { and completed standard } \\
\text { documents }\end{array}$ & Yes & Between members \\
\hline $\begin{array}{l}\text { User/implementer access to } \\
\text { interfaces }\end{array}$ & Yes & Between members \\
\hline \begin{tabular}{l} 
On-going support \\
\hline
\end{tabular} & $\begin{array}{l}\text { Through standard's } \\
\text { life cycle }\end{array}$ & $\begin{array}{l}\text { At discretion of } \\
\text { members }\end{array}$ \\
\hline
\end{tabular}

issues such as competitive strategy decisions (Besen and Farrell 1994; Gabel 1991; Iversen 2001; West and Dedrick 2000), infrastructure investment costs (Christiaanse et al. 2004), the availability of complementary assets (Damsgaard and Truex 2000; Rice 2001; Tassey 2000), and their impacts on the size of production costs (Feng 2003; Iversen 2001). In the later stages of the technology's adoption and diffusion, research on the role of standards has focused on issues such as competitive advantage and network dominance through network externalities and lock-in (Funk and Mehte 2001; Sirkemaa 2002), the introduction of price competition (Besen and Farrell 1994; Farrell and Saloner 1985), and the availability of complementary assets (Funk and Mehte 2001; Tassey 2000).

Finally, from a social perspective, research in the area of standards has highlighted their role as a means to store and preserve knowledge (Damsgaard and Truex 2000; Feng 2003; King et al. 1994), influence the variety of technology available (Farrell and Saloner 1985; Jakobs 2001; Tassey 2000), impact user uncertainty and risk (Damsgaard and Truex 2000; Funk and Mehte 2001), as a means of quality control (Feng 2003; Tassey 2000), and on the alignment of users' actions (Feng 2003).

\section{DOI THEORY AND BASE IT INNOVATIONS}

The value of DOI theory value is well established, as evidenced by its widespread use to explain the adoption and diffusion of a range of technological innovations. When 
applied to certain classes of technology that do not meet the model's underlying assumptions, modification and extension of the theory is required (Fichman 2000). There have been a number of general criticisms made of DOI theory and of its underlying assumptions in the context of its application to network-based innovations and complex IS innovations, both of which are considered relevant within the context of the current paper. Following a review of these challenges to the theory's underlying assumptions, existing extensions to DOI theory in the context of base IT innovations are discussed in order to provide a basis for the proposed research framework.

\subsection{Complex Innovations, Network-Based Technologies and DOI}

The first of these assumptions relates to the adoption decision process related to complex IS. It has been argued that the use of DOI in the analysis of adoption issues relating to any complex organizational IS falls short because of the complexity present in the IS structure and the need for organizational rather than individual decision-making processes to adequately understand these complexities (Attewell 1992; Bayer and Melone 1989; Fichman 2000).

The lack of consideration of market characteristics and factors present within a network environment have been identified as one factor that minimizes the applicability of the theory within the context of CNIS. The impact of network effects on complex network technologies has been widely studied (see, for example, Farrell and Saloner 1985; Katz and Shapiro 1985, 1986; Shapiro and Varian 1999). The absence of consideration of the collective adoption behaviors arising in the presence of network externalities within this technology context is one area identified as being a relevant weakness of DOI theory (Fichman 1992, 2000; Gallivan 2001; Lyytinen and Damsgaard 2001).

The assumption that the innovation emerges as a complete and discrete package also comes into question in criticisms of DOI theory and its application to complex IT innovations (Fichman 2000). In complex technologies where different interrelated components and a high level of technical knowledge are required for the technology to operate, such components (for example, applications, telecommunications services, and standards; Lyytinen and Damsgaard 2001) and knowledge are often distinct from the discrete package view of an innovation. The traditional view of diffusion as a process involving the communication of information, rather than technical knowledge, means that additional demands are placed on both the supplier in terms of communication requirements and the potential adopter in terms of organizational learning (Attewell 1992, Newell et al. 2000). A point further related to this assumption is that by viewing all classes of innovation as sharing similar attributes, the complexity in certain IS innovations can be misrepresented, as not all classes of IS innovation can be described using common characteristics (Lyytinen and Damsgaard 2001).

A third assumption underlying the DOI theory is that the primary barrier to adoption is lack of information of innovation's existence and benefits (Fichman 2000). It has been argued that barriers to diffusion can be intentionally put in place to limit diffusion of innovations through the management of the elements diffusion (innovation, com- 
munication, time, and the social system), as identified by Rogers (1962) and Baskerville and Preis-Heje (1998). If this view is accepted, then a lack of information is only one aspect that can potentially act as a barrier to adoption. The complexity of the innovation, and the resulting knowledge requirements placed on the adopting organization, may also be viewed as a potential barrier to adoption (Attewell 1992, Gallivan 2001). In circumstances where organizations are aware of the existence an innovation, but lack the capabilities necessary to adopt it, again the primary barrier is not the lack of information regarding the existence of the innovation. Also, related to this assumption is the finding that adoption is not a "function of available information, preference functions, risk and adopter's properties" (Lyytinen and Damsgaard 2001, p. 10). Instead, it has been shown that other factors, such as a choice of business strategy can serve to influence adoption decisions (Lyytinen and Damsgaard 2001). Related to this point is the criticism that DOI theory exhibits a pro-innovation bias (Abrahamson 1991). It has been argued that DOI theory does not sufficiently take into account non-adoption decisions, a necessary factor as not every innovation is adopted (Geroski 2000).

By assuming that adoption is free from coercion (Fichman 2000; Gallivan 2001; Lyytinen and Damsgaard 2001), and is only related to relationships between the supply and demand side, interactions that allow a rational choice pose problems in the area of certain adoption IS contexts. Such a view does not fully consider the role of entities such as internal decision makers and external institutions that can mandate the adoption of an innovation (Abrahamson 1991; Lyytinen and Damsgaard 2001; King et al. 1994).

\subsection{Existing Extensions to DOI Theory in the Context of Base IT Innovations}

The DOI model is regarded as having a strong theoretical base and has been extensively used, with modifications and extensions, in the investigation of IS innovations of varying types. This reflects the view that the fundamental differences in adoption situation require theory development that focuses on the distinctive characteristics of the adoption context (Abrahamson 1991; Fichman 2000; Lyytinen and Damsgaard 2001; Munkvold 1998). While the dominant view of standards emerges from an economic justification of their use, the impact felt by standards and standardization covers a broader range of issues than illustrated by a discussion based in an economic or management oriented arena (Iversen 2001). Consequently, the adaptation of the DOI model to account for specific characteristics related to standards adoption is required. In order to do so, aspects of earlier studies focusing on innovations of the same type (i.e., base IT innovations), are drawn upon.

Somewhat lacking in the literature is an empirical investigation of the relationship between a system oriented technical view and the more organizationally oriented economic or strategic view of standards. While the importance of technical standards for interoperability in an ICT setting has been suggested by Williams (1999), in the context of the need for a combined innovation and economic focus on standards, there is limited empirical research evident in the area. There are a number of examples of research that have moved toward such a combination. First, Nelson and Shaw (2003) have taken an innovation diffusion view of interorganizational system standards and process innova- 
tions in order to investigate the movement away from earlier views of IOS technologies (primarily EDI) and toward modern-day IOS solutions (i.e., primarily internet enabled approaches). In addition to a focus on innovation attributes, also included are measures of organizational readiness, the external environment, and the standards development organization. By including these measures, a combined view of issues impacting standards adoption from the points of view of the technology, the organization, and the environment were examined. A second example of such research involves the investigation of a specific Internet standards (IPv6) adoption by Internet service providers conducted by Hovav et al. (2004). This work focuses on the adoption of a technical standard using an extended version of the diffusion of innovation theory. Both the perceived attributes of the standard in question and issues relating to the broader "environmental conduciveness" to the standard's adoption are examined. Here, environmental conduciveness incorporates extra-organizational economic factors, and threby moves toward a more unified view of standards adoption issues. In the case of emergent complex network information systems, substantial moves toward development remain to be completed, and as such competing paths between open and proprietary standards still exist. The existence of such competing paths means the trade-off between the technical and economic impacts of standards remains an issue. A final example of research which has moved toward a more unified view of the issues involved in standards adoption was conducted by Chau and Tam (1997), and focused on the adoption of open systems in the context of organizational IT infrastructures. A number of technology (innovation) attributes, market uncertainty, and the organization's existing technological context were considered in the research model.

While these research efforts provide a level of guidance to the development of the proposed research framework, there are important contextual differences. While these earlier efforts have related loci of adoption (i.e., organizational or interorganizational settings), the reasons for the standards adoption differ. In the identified studies, the base IT innovations have been adopted as a means to enable the development of organizational or interorganizational IT infrastructures, rather than as an input into a core product development. As such, the organizations adopting the standards can be viewed as primary users of the standard, rather than secondary users, as is the case with the AmI standards, which are of interest within the current research. While there is likely to be an overlap in the factors impacting the standards adoption decision between these types of users, the potential for difference remains.

\section{TOWARD A MODEL FOR UNDERSTANDING THE ADOPTION OF CNIS STANDARDS}

An extension of the Rogers' diffusion of innovation theory is required in order to explain the adoption of interoperability standards within the context of CNIS. This extension is required in order to extend the DOI theory's standalone view of the organization and to incorporate both factors relating to the context of the standard choices under consideration and the technological context in which the standards will be used. In doing so, a means of analysis may be provided for understanding the adoption choices made by technology vendors in relation to open or closed interoperability standards for 
CNIS to support ambient intelligence. In particular, the factors influencing the adoption or non-adoption of interoperability standards are not confined to purely a system view in which maximum interoperability is always the objective. Rather there is a trade-off between the system oriented goal of interoperability, and the range of economic factors relating to optimal organizational performance in the market, as was illustrated through the identification of the multiple roles and impacts of standards from the technical, business and economic, and social perspectives. Figure 2 illustrates our proposed extension by illustrating that organizational, external, and innovation (standard) contexts impact the adoption process.

At the level of standard (innovation) context, Rogers' DOI model proposes five innovation attributes as being useful in predicting innovation adoption. These are relative advantage, compatibility, complexity, trialability, and observability. Following the findings of Tornatzky and Klein (1982), only the three most consistently identified attributes of relative advantage, compatibility, and complexity are included in the proposed model. In line with Rogers' view of relative advantage, it is defined here as the degree to which the adopter perceives the standard as being better than that which it supersedes. In contrast to earlier approaches, the compatibility attribute has been broken down into a number of component parts. First, the perceived strategic compatibility of the type of standards (i.e., open versus closed) being adopted is included. The decision to partake in inter-technology (i.e., within a technology class) or in intra-technology (i.e., between technology) classes is reliant on the adoption or non-adoption of compatibility standards, as proposed by Besen and Farrell (1994) and Shapiro (1998). As such, the compatibility between the candidate standards and the existing or desired approach to organizational strategy warrants investigation. Second, the technical compatibility of the standards being adopted in relation to backward compatibility (between new products based on the emerging standard and existing product offerings and internal systems) can impact the adoption decision. Finally, the compatibility between standards being adopted for inclusion within a new product requires attention. This factor is included in order to assess how interdependencies between standards of different levels (i.e., at the application, data, and network levels) can impact the adoption decision.

The complexity of the standard is considered in two ways. First, the structural complexity of the system and its relationship to the standards being adopted is included. As discussed, the structural complexity of complex network-based systems requires modularity in design to facilitate interaction between system elements. The decision to adopt open or closed interoperability standards can impact on the systems' ability to function, and as such, the organization's perception of the technical requirements of the system is an important consideration. The second aspect of complexity relates to the knowledge requirements of complex innovations and the organization's capability to respond to them. The inclusion of such a factor is line with the arguments of Attewell (1992) and Gallivan (2001), who point out that with complex innovations a high level of technical knowledge may be required, with the resulting knowledge requirements being a potential barrier to adoption.

Given the complexities involved in the decision process surrounding standards adoption, and the weakness of DOI theory in adequately understanding such complexities, the organizational context level identifies a number of factors broadly termed political issues that require consideration (see Figure 2). First, the level of support given 


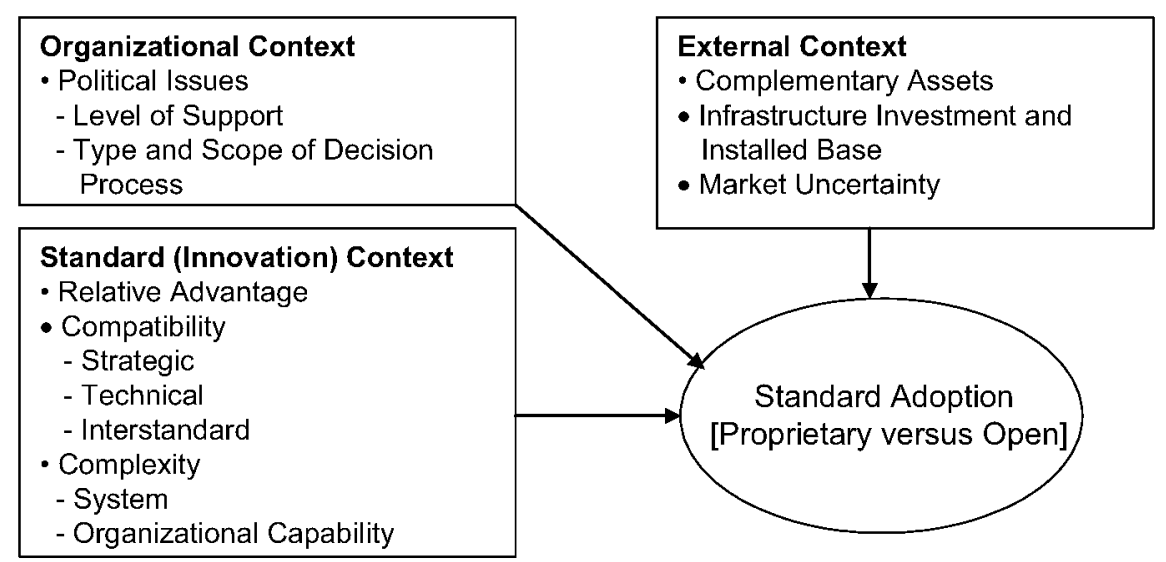

Figure 2. Model of Standards Adoption in a Complex Network-Based System

to the standards adoption process and the issue of mandated adoption can both have an effect on adoption. The scope of the decision process, as related to the extent of collaboration at an individual, organizational unit, or interorganizational level is an important consideration. Such issues may be linked to organizational or interorganizational strategy or existing participation in standards development processes. Factors surrounding organizational innovativeness were omitted following other adoption factor studies focused on similar innovation types (see Hovav et al. 2004). The inclusion of such factors may, however, be relevant as controls (for example, the use of size; Nelson and Shaw 2003), depending on the context in which the model is applied.

At the external context level, three issues are examined for their impact on adoption (see Figure 2). First is the issue of complementary assets, that is, products that can be used with the technology-for example, software is a complementary asset to an operating system, in that only certain software can be used with certain operating systems. The decision on the choice of compatibility standards made by vendors will also impact the type and number of complementary assets available for adopters of the technology. Dedrick and West (2003) have argued that a key barrier to the adoption of a new standard is the availability of complementary assets relating to the existing standard. The development of technology based on proprietary standards can limit the availability of complementary assets produced by other companies. In certain circumstances such a situation is desirable to a vendor, particularly where they intend to develop a full range of proprietary complementary assets and wish to limit competition or imitation of their products. In the area of network technologies, however, it is often the case that limiting the availability of complementary assets is not a desirable strategy. In many circumstances, one vendor does not have the capability to produce the necessary quantity and quality of complementary components required to successfully complete the construction of a network based system (Rice 2001). The lack of such a capability could, as Tassey (2000) argues, be a consequence of unwillingness to diversify operations into fields in which they have no comparative advantage, or from having limited access to resources (e.g., finance or knowledge). 
The second issue relates to the issue of infrastructure investment and the existing installed base. The underlying technical infrastructure (e.g., the communications systems) for a large scale system requires substantial investment to implement and maintain. In existing complex network-based information system, the costs vary depending on the type of network involved. In the case of intra-organizational or closed interorganizational systems this cost is borne by the organization or organizational network involved due to the proprietary nature of such systems. The implementation of networkbased systems based of a proprietary nature requires up-front investment in assets (Christiaanse et al. 2004). Such a situation means that the addition of new network members is costly, leading to a limiting effect on the number of users (Afuah 2003). In order to utilize an existing infrastructure, the reliance on standards is an important issue. In the case of the Internet, the result of using a low-cost, open standard means that "anyone, anywhere" can connect to it once the required communications protocols are implemented (Afuah 2003). In relation to the installed base, given the characteristic of network effects in network-based technologies, the existence of a system based on standards of a certain type (i.e., open or closed) can be influential in the adoption decision, and as such, its consideration is warranted in the context of new standards adoption.

The final factor in the external context area relates to market uncertainty, and draws upon Chau and Tam's (1997) open systems adoption model. Markus (1987) demonstrated that the characteristics of network markets show that once a critical mass of users adopt the technology, its growth will become self-sustaining. Karlsbjerg (2002) has argued that should the technology be based on proprietary standards, the standard owner can increase switching costs leading to user lock-in, meaning that they will be less likely to move to a competing technology due to uncertainty or risk associated with leaving an established network (Damsgaard and Truex 2000), or problems with a lack of interoperability between competing standards. It is with this in mind that the consideration of market conditions such as the existing stage of market evolution and the presence of existing standards is included in the analysis of the adoption decision.

\section{CONCLUSION}

Using existing research on the diffusion of base IT innovations and standards, this paper has developed a model for identifying the issues surrounding the adoption of open or closed interoperability standards in the context of emerging forms of CNIS. However, the model is empirically untested, and research is needed to verify and refine it for use in practice. In order to do so, a number of operational challenges are presented. First, the selection of a unit of analysis presents choices. Given the scale of the systems under consideration, the use of a single organization or a single technology class has the potential to give misleading results. The preselection of a single standard could also limit the study by omitting non-adopting organizations, and introduce proinnovation bias by focusing only on successful standards. It is suggested that an industry sector unit of analysis (following Reimers et al. 2004) be used in order to overcome these problems. A second challenge presented is availability of data. The area of AmI is currently underdeveloped with the majority of applications deployed as prototypes. Given the prominence of consumer electronics (CE) in the many AmI usage 
scenarios put forward and the fact that much AmI research and development has occurred within this area, the model will be tested within the European CE sector. In order examine such a sector, a number of stakeholders must be considered, for example, $\mathrm{CE}$ manufacturers, software and services development organizations, and telecommunications service providers.

This model is timely in the context of the need of organizations to assess emerging technologies used to build CNIS. Given the ongoing development of technologies capable of supporting the AmI vision, the requirement of organizations to adequately evaluate standards provides a practical outlet for such a model.

\section{Acknowledgment}

This research is based on research funded by the European Commission via IST Project 004337, CALIBRE (http://www.calibre.ie).

\section{References}

Abowd, G., and Mynatt, E. "Charting Past, Present and Future Research in Ubiquitous Computing" ACM Transactions on Computer-human Interaction (7), 2000, pp. $29-58$.

Abowd, G., Mynatt, E., and Rodden, T. "The Human Experience," IEEE Pervasive Computing (1), 2002, pp. 48-57.

Abrahamson, E. "Managerial Fads and Fashions: The Diffusion and Rejection of Innovations," Academy of Management Journal (16), 1991, pp. 586-612.

Afuah, A. "Redefining Firm Boundaries in the Face of the Internet: Are Firms Really Shrinking?" Academy of Management Review (28), 2003, pp. 34-53.

Alvai, M., and Carlson, P. "A Review of MIS Research and Disciplinary Development," Journal of Management Information Systems (3), 1992, pp. 45-62.

Attewell, P. "Technology Diffusion and Organizational Learning: The Case of Business Computing," Organization Science (3), 1992, pp. 1-19.

Banavar, G., and Bernstein, A. "Software Infrastructure and Design Challenges for Ubiquitous Computing Applications," Communications of the ACM (45), 2002, pp. 92-96.

Baskerville, R., and Preis-Heje, J. "Information Technology Diffusion: Building Positive Barriers," European Journal of Information Systems (7), 1998, pp. 17-28.

Bayer, J., and Melone, N. "A Critique of Diffusion Theory as a Managerial Framework for Understanding Adoption of Software Engineering Innovations," Journal of Systems and Software (9), 1989, pp. 161-166.

Besen, S. M., and Farrell, J. "Choosing How to Compete: Strategies and Tactics in Standardization," Journal of Economic Perspectives (8), 1994, pp. 117-131.

Boddupalli, P., Al-Bin-Ali, F., Davies, N., Friday, A., Storz, O., and Wu, M. "Payment Support in Ubiquitous Computing Environments," in Proceedings of the Fifth IEEE Workshop on Mobile Computing Systems and Applications, Los Alamitos, CA: IEEE Computer Society Press, October 2003, p. 110.

Borriello, G., Chalmers, M., Lamarea, A., and Nixon, P. "Delivering Real-World Ubiquitous Location Systems," Communications of the ACM (48), 2005, pp. 36-41.

Chau, P. Y. K., and Tam, K. Y. "Factors Affecting the Adoption of Open Systems: An Exploratory Study," MIS Quarterly (21:1), 1997, pp. 1-24.

Chen, W., and Hirschheim, R. A. "A Paradigatic and Methodological Examination of Information Systems Research from 1991 to 2001," Information Systems Journal (14:3), 2004, pp. 197-235. 
Chen, L., and Tan, J. "Technology Adaption in E-Commerce: Key Determinants of Virtual Stores Acceptance," European Management Journal (22), 2004, pp. 74-86.

Christiaanse, E., Van Diepen, T., and Damsgaard, J. "Proprietary Versus Internet Technologies and the Adoption and Impact of Electronic Marketplaces," Journal of Strategic Information Systems (13), 2004, pp. 151-165.

Chung, J., Lin, K., and Mathieu, R. G. "Web Services Computing: Advancing Software Interoperability," Computer (36), 2003, pp. 35-37.

Cilliers, P. Complexity and Postmodernism: Understanding Complex Systems, London: Routledge, 1998.

Claver, E., Gonzales, R., and Llopis, J. "An Analysis of Research in Information Systems," Information and Management (37), 2000, pp. 181-195.

Culnan, M. J. "Mapping the Intellectual Structures of MIS, 1980-1985: A Co-citation Analysis," MIS Quarterly (11), 1987, pp. 340-353.

Damsgaard, J., and Truex, D. "Binary Trading Relations and the Limits of EDI Standards: The Procrustean Bed of Standards," European Journal of Information Systems (9), 2004, pp. 173-188.

Davies, N., and Gellersen, H.-W. "Beyond Prototypes: Challenges in Deploying Ubiquitous Computing Systems," IEEE Pervasive Computing (1), 2002, pp. 26-35.

Dedrick, J., and West, J. "Why Firms Adopt Open Source Platforms: Grounded Theory of Innovation and Standards Adoption," in J. L. King and K. Lyytinen (eds.), Proceedings of the MIS Quarterly Special Issue Workshop on Standard Making: A Critical Research Frontier for Information Systems, Seattle, WA, 2003, pp. 236-257.

Drury, D. H., and Farhoomand, A. "Innovation Diffusion and Implementation," International Journal of Innovation Management (3), 1999, pp. 133-157.

Ducatel, K., Bogdanowicz, Scapolo, F., Leijten, J., and Burgelman, J.-C. "Scenarios for Ambient Intelligence in 2010," Technical Report, Information Society Technology Advisory Group (ISTAG), European Commission, February 2001 (available from ftp://ftp.cordis.lu/pub/ist/docs/istagscenarios2010.pdf).

Ethiraj, S. K., and Levinthal, D. "Modularity and Innovation in Complex Systems," Management Science (50), 2004, pp. 159-173.

Farrell, J., and Saloner, G. "Standardization, Compatibility, and Innovation," Rand Journal of Economics (16), 1985, pp. 70-83.

Feng, P. "Studying Standardization: A Review of the Literature," in T. M. Egyedi, K. Krechmer, and K. Jakobs (eds.), Proceedings of the $3^{\text {rd }}$ IEEE Conference on Standardization and Innovation in Information Technology, Los Alamitos, CA: IEEE Computer Society Press, 2003.

Fichman, R. G. "Information Technology Diffusion: A Review of Empirical Research," in J. I. DeGross, J. D. Becker, and J. J. Elam (eds.), Proceedings of the $13^{\text {th }}$ International Conference on Information Systems, Dallas, TX, December 1992, pp. 195-206.

Fichman, R. G. "The Diffusion and Assimilation of Information Technology Innovations," in R. W. Zmud (ed.), Framing the Domains of it Management: Projecting the Future Through the Past, Cincinnati, OH: Pinnaflex Publishing, 2000.

Funk, J. L., and Mehte, D. T. "Market- and Committee-Based Mechanisms in the Creation and Diffusion of Global Industry Standards: The Case of Mobile Communication," Research Policy (30), 2001, pp. 589-610.

Gabel, H. L. Competitive Strategies for Product Standards: The Strategic Use of Compatibility Standards for Competitive Advantage, Berkshire, England: McGraw Hill Book Company, 1991.

Gallivan, M. J. "Organizational Adoption and Assimilation of Complex Technological Innovations: Development and Application of a New Framework," ACMSIGMIS Database (32), 2001, pp. 51-85.

Garlan, D., Siewiorek, D., and Steenkiste, P. "Project Aura: Toward Distraction-Free Pervasive Computing," Pervasive Computing (1), 2002, pp. 22-31. 
Geroski, P. A. "Models of Technology Diffusion," Research Policy (29), 2000, pp. 603-625. Helal, S. "Programming Pervasive Spaces," Pervasive Computing (4), 2005, pp. 84-87.

Henricksen, K., Indulska, J., and Rakotonirainy, A. "Infrastrucure for Pervasive Computing: Challenges," in K. Bauknecht, W. Brauer, and T. A. Muck (eds.), Proceedings of the Informatik 2001: Workshop on Pervasive Computing, Vienna, Austria, 2001, pp. 214-222.

Hovav, A., Patnayakuni, R., and Schuff, D. "A Model of Internet Standards Adoption: The Case of IPV6," Information Systems Journal (14), 2004, pp. 265-294.

Islam, N., and Fayad, M. "Toward Ubiquitous Acceptance of Ubiquitous Computing," Communications of the ACM (46), 2003, pp. 89-92.

Iversen, E. J. "Raising Standards: Innovation and the Emerging Global Standardization Environment for ICTs," in T. D. Schoechle and C. B. Wagner (eds.), Proceedings of the $2^{\text {nd }} I E E E$ Conference on Standardization and Innovation in Information Technology, Los Alamitos, CA: IEEE Computer Society Press, 2001, pp. 13-24.

Jakobs, K. "A Broader View on Some Forces Shaping Standardization," in T. D. Schoechle and C. B. Wagner (eds.), Proceedings of the Second IEEE Conference on Standardization and Innovation in Information Technology, Los Alamitos, CA: IEEE Computer Society Press, 2001, pp. 133-143.

Karlsbjerg, J. "Staying Outside the Mainstream: An Empirical Study of Standards Choices," in R. H. Sprague (ed.), Proceedings of the $35^{\text {th }}$ Hawaii International Conference on System Sciences (Volume 8), Los Alamitos, CA: IEEE Computer Society Press, 2002, pp. 3335-3343.

Katz, M. L., and Shapiro, C. "Network Externalities, Competition, and Compatibility," The American Economic Review (75), 1985, pp. 424-440.

Katz, M. L., and Shapiro, C. "Technology Adoption in the Presence of Network Externalities," Journal of Political Economy (94), 1986, pp. 822-841.

King, J. L., Gurbaxani, V., Kraemer, K. L., McFarlan, F. W., Raman, K. S., and Yap, C. S. "Institutional Factors in Information Technology Innovation," Information Systems Research (5), 1994, pp. 139-169.

Krechmer, K. "The Meaning of Open Standards," in D. King and A. Dennis (eds.), Proceedings of the $38^{\text {th }}$ Hawaii International Conference on Systems Sciences, Los Alamitos, CA: IEEE Computer Society Press, January 2005, p. 204b.

Kumar, R. L. "A Framework for Assessing the Business Value of Information Technology Infrastructures," Journal of Management Information Systems (21:2), 2004, pp. 11-32.

Langlois, R. N. "Modularity in Technology and Organization," Journal of Economic Behavior and Organization (49), 2002, pp. 19-37.

Lassila, O. "Serendipitous Interoperability," in E. Hyvonen (ed.), Semantic Web Kick-off in Finland-Vision, Technologies, Research and Applications, Helsinki, Finland: HIIT Publications, 2002, pp. 243-256.

Lee, G., and Xia, W. "Development of a Measure to Assess the Complexity of Information Systems Development Projects," in L. Applegate, R. Galliers, and J. I. DeGross (eds.),

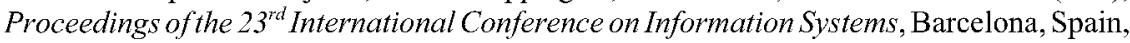
2002, pp. 79-88.

Lyytinen, K., and Damsgaard, J. "What's Wrong with the Diffusion of Innovation Theory? The Case of a Complex and Networked Technology," in M. A. Ardis and B. L. Marcolin (eds.), Diffusing Software Products and Process Innovations, Boston: Kluwer Academic Publishers, 2001, pp. 173-190.

Lyytinen, K., and Rose, G. M. "Disruptive Information System Innovation: The Case of Internet Computing," Information Systems Journal (13), 2003, pp. 301-330.

Lyytinen, K., Rose, G. M., and Welke, R. "The Brave New World of Development in the Internetwork Computing Architecture (Internca): Or How Distributed Computing Platforms Will Change Systems Development," Information Systems Journal (8), 1998, pp. 241-253.

Lyytinen, K., and Yoo, Y. "The Next Wave of Nomadic Computing: A Research Agenda for Information Systems Research," Information Systems Research (13), 2002, pp. 377-388. 
Maekawa, M. "ITS (Intelligent Transportation Systems) Solutions," NEC Journal of Advanced Technology (1), 2004, pp. 194-199.

Markus, M. L. "Toward a 'Critical Mass' Theory of Interactive Media: Universal Access, Interdependence and Diffusion," Communications Research (14), 1987, pp. 491-511.

Munkvold, B. E. "Adoption and Diffusion of Collaborative Technology in Interorganizational Networks," in J. F. Nunamaker (ed.), Proceedings of the $31^{\text {st }}$ Hawaii International Conference on Systems Sciences (Volume 1), Los Alamitos, CA: IEEE Computer Society Press, 1998, pp. 424-433.

Nakajima, T., Ishikawa, H., Tokunaga, E., and Stajano, F. "Technology Challenges for Building Internet-Scale Ubiquitous Computing," Proceedings of the Seventh IEEE Workshop on Object-Oriented Real-Time Dependable Systems (Words 2002), Los Alamitos, CA: IEEE Computer Society Press, 2002, pp. 171-179.

Nelson, M. L., and Shaw, M. J. "The Adoption and Diffusion of Interorganizational System Standards and Process Innovations," in J. L. King and K. Lyytinen (eds.), Proceedings of the MIS Quarterly Special Issue Workshop on Standard Making: A Critical Research Frontier for Information Systems, Seattle, WA, 2003, pp. 258-301.

Newell, S., Swan, J. A., and Galliers, R. D. "A Knowledge-Focused Perspective on the Diffusion and Adoption of Complex Information Technologies: The BPR Example," Information Systems Journal (10), 2000, pp. 239-259.

Orlikowski, W., and Baroudi, J. J. "Studying Information Technology in Organizations: Research Approaches and Assumptions," Information Systems Research (2), 1991, pp. 1-28.

Prekop, P., and Burnett, M. "Activities, Context and Ubiquitous Computing," Computer Communications (26), 2003, pp. 1168-1176.

Reimers, K., Johnston, R. B., and Klein, S. "The Shaping of Interorganizational Information Systems: Main Design Considerations of an International Comparative Research Project," in J. Gricar and G. Lenart (eds.), Proceedings of the $17^{\text {th }}$ Bled E-Commerce Conference, eGlobal, Bled, Slovenia, June 21-23, 2004.

Rice, J. "Collaboration and Competition in Emerging Standards: An Assessment of the Implications for Knowledge Management," in T. D. Schoechle and C. B. Wagner (eds.), Proceedings of the $2^{\text {nd }}$ IEEE Conference on Standardization and Innovation in Information Technology, Los Alamitos, CA: IEEE Computer Society Press, 2001, pp. 272-281.

Rogers, E. Diffusion of Innovations, New York: Free Press, 1962.

Romano, N. C., and Fjermestad, J. "Electronic Commerce Customer Relationship Management: An Assessment of Research," International Journal of Electronic Commerce (6), 2002, pp. 61-113.

Shapiro, C. "Setting Compatibility Standards: Cooperation or Collusion?," paper presented at the Conference of the Engelberg Center on Innovation Law and Policy, La Pietra, Italy, 1998.

Shapiro, C., and Varian, H. R. Information Rules: A Strategic Guide to the Network Economy, Boston: Harvard Business School Press, 1999.

Sharifi, H., and Zhang, Z. "A Methodology for Achieving Agility in Manufacturing Organizations: An Introduction," International Journal of Production Economics (62), 1999, pp. 7-22.

Simon, H. A. "The Architecture of Complexity," Proceedings of the American Philosophical Society (106), 1962, pp. 467-482.

Sirkemaa, S. "IT Infrastructure Management and Standards," in P. Srimani and H. Yu (eds.), Proceedings of the International Conference on Information Technology: Coding and Computing, Los Alamitos, CA: IEEE Computer Society Press, 2002, pp. 201-206.

Sprott, D. "Componentizing the Enterprise Application Packages," Communications of the ACM (43), 2000, pp. 63-69.

Stegwee, R. A., and Rukanova, B. D. "Identification of Different Types of Standards for Domain-Specific Interoperability," in in Proceedings of the MIS Quarterly Special Issue 
Workshop on Standard Making: A Critical Research Frontier for Information Systems, Seattle, WA, 2003.

Strand, E. J., Mehta, R. P., and Jairam, R. "Applications Thrive on Open Systems Standards," Standardview (2), 1994, pp. 148-154.

Tassey, G. "Standardization in Technology-Based Markets," Research Policy (29), 2000, pp. $587-602$.

Thomke, E., and Reinersten, D. G. "Agile Product Development: Managing Development Flexibility in Uncertain Environments," California Management Review, Fall 1998, pp. 8-30.

Tornatzky, L. G., and Klein, K. J. "Innovation Characteristics and Innovation Adoption Implementation: A Meta-Analysis of Findings," IEEE Transactions on Engineering Management (EM-29), 1982, pp. 28-45.

Weiser, M. "The Computer for the $21^{\text {sl }}$ Century," Scientific American (265), 1991, pp. 94-104. West, J. "What Are Open Standards? Implications for Adoption, Competition and Policy," paper presented at the Standards and Public Policy Conference, Federal Reserve Bank of Chicago, Chicago, Illinois, 2004.

West, J., and Dedrick, J. "Innovation and Control in Standards Architectures: The Rise and Fall of Japan's PC-98," Information Systems Research (11), 2000, pp. 197-216.

Williams, R. "ICT Standard Setting from an Innovation Studies Perspective," in First IEEE Conference on Standardization and Innovation in Information Technology, Los Alamitos, CA: IEEE Computer Society Press, September 1999, pp. 15-17

\section{About the Authors}

David Kelly is currently pursuing a Ph.D. in Information Systems at University College Cork. His research interests include innovation adoption, ambient intelligence, standards, and open-source software. David can be reached at d.kelly@ucc.ie.

Joseph Feller is a senior lecturer in Business Information Systems, University College Cork, Ireland. His work on open source software includes coauthorship of two books (Perspectives on Free and Open Source Software, The MIT Press, 2005, and Understanding Open Source Software Development, Addison-Wesley, 2002) as well as international conference and journal papers. He coauthored "A Framework Analysis of the Open Source Software Development Paradigm," which was awarded Best Paper on Conference Theme at the $21^{\text {st }}$ International Conference on Information Systems (ICIS 2000). Joseph was the lead organizer of the IEE/ACM workshop series on Open Source Software Engineering from 2001 through 2005, and has been a speaker and panelist on the topic at academic conferences, industry workshops, and European Commission briefings and roundtables. Joseph is a member of the EU FP6 Coordination action project CALIBRE (www.calibre.ie), co-leading the dissemination and awareness work package and conducting research on open source software business models. He can be reached at jfeller@afis.ucc.ie.

Patrick Finnegan holds a Ph.D. in Information Systems from the University of Warwick, and is currently a senior lecturer in Management Information Systems at University College Cork. His research interests include electronic business and IS strategy. He has published his research in a number of international journals and conferences including The International Journal of Electronic Commerce, Information Technology \& People, DataBase, Electronic Markets, The Information Systems Journal, the European Conference on Information Systems, the International Conference on Information Systems, and the Americas Conference on Information Systems. Patrick can be reached at pfinnegan@afis.ucc.ie. 